\title{
Minimizing the effect of TBI-related physical sequelae on vocational
}

\section{return}

\author{
Shane McNamee, MD; ${ }^{1-2 *}$ William Walker, MD; ${ }^{2}$ David X. Cifu, MD; ${ }^{1-2}$ Paul H. Wehman, PhD $^{2}$ \\ ${ }^{1}$ Department of Physical Medicine and Rehabilitation, Hunter Holmes McGuire Richmond Department of Veterans \\ Affairs Medical Center, Richmond, VA; ${ }^{2}$ Department of Physical Medicine and Rehabilitation, Virginia Commonwealth \\ University, Richmond, VA
}

\begin{abstract}
This article evaluated the common physical sequelae that affect return to work (RTW) after traumatic brain injury (TBI). We performed a Medline search and evaluation of current TBI rehabilitation texts. The information presented is a combination of published literature and clinical guidelines. The limitations faced by many patients with TBI can best be overcome through clever job search, job redesign, and community linkages with business and industry that are willing to partner in helping the patient with TBI regain employment. The physician plays a key role in communicating suggestions to the vocational specialist. The comorbidities described represent challenges to successful RTW. These problems are recurrent, long-term, and clearly affect job procurement, nature of job, level of required support, and likelihood of job retention. Conversely, these challenges should not be viewed as impenetrable obstacles. With appropriate supports such as compensatory strategies, job coaching, assistive technology, medical management, and job restructuring, successful RTW is viable option. Physicians must focus on employment outcomes in real jobs and not settle for volunteer work, sheltered work, or assessment and planning. Individuals should be placed in real work for real pay. Through close collaboration between the survivor of TBI, the physician, the vocational specialist, and community resources, successful employment for survivors of TBI is possible and must be prescribed a high value.
\end{abstract}

Key words: community reintegration, employment, functional restoration, rehabilitation, return to work, school reintegration, TBI, traumatic brain injury, vocational return, work reintegration.

\section{INTRODUCTION}

Traumatic brain injury (TBI) is a leading cause of worldwide disability, with one estimate showing a loss of 56 billion dollars in economic productivity [1]. Its economic impact is large because it has a predilection to affect young people on the verge of their most productive years. As understanding of TBI has increased, so has the focus on vocational return following injury [2]. Within the continuum of functional restoration, vocational return is regarded as the most durable sign of successful community return [3]. Employment becomes a challenging, if not unlikely, feat to attain because of a myriad of cognitive, physical, and psychosocial problems. Meaningful productive employment enhances self-esteem, financial status,

\footnotetext{
Abbreviations: $\mathrm{CPT}=$ computerized posturography testing, $\mathrm{CRP}=$ community rehabilitation program, $\mathrm{GPB}=$ grooved pegboard (test), $\mathrm{HA}=$ headache, $\mathrm{HO}=$ heterotopic ossification, NSAID = nonsteroidal anti-inflammatory drug, PTHA = posttraumatic HA, RTW = return to work, TBI = traumatic brain injury, UFOV = Useful Field of View (test).

*Address all correspondence to Shane McNamee, MD; Department of Physical Medicine and Rehabilitation, Richmond VAMC, 1201 Broad Rock Boulevard, Attn 117, Richmond, VA 23249; 804-675-5117; fax: 804-675-6989.

Email: shane.mcnamee@va.gov

DOI:10.1682/JRRD.2008.08.0106
} 
and one's overall quality of life, yet for many individuals with TBI, return to productive employment seems unlikely [4-5]. Furthermore, vocational return is increasingly viewed as a means of enhancing cognitive, behavioral, and physical recovery after the acute rehabilitation phase. Because of this and other factors, vocational rehabilitation strategies to assist survivors of TBI are of utmost importance.

The TBI literature has established reliable indicators of functional recovery, such as functional mobility, selfcare, and community return [6]. Prognostication of vocational return is much more complex given the impact of personality characteristics and environmental, economic, and cultural factors. Several factors have been identified that add predictive value. These include injury severity, age at time of injury, number of neuropsychological deficits, level of physical disability, premorbid employment, and educational level [3,7-10].

A brief review of return to work (RTW) literature reveals contradicting findings regarding the effect of injury severity on RTW [11-13]. RTW rates have been tied to injury severity [9,13-14], although not all investigators have found a relationship between injury severity and RTW [12,15-16]. Despite the varying results, it is important to note that some individuals who sustained very severe injuries are able to return to employment relatively unhindered $[7,13]$.

The specific types of cognitive, behavioral, physical, and psychosocial impairments associated with TBI of an individual may be more predictive of his or her RTW than the measure of injury severity [17]. For example, significant physical disability, psychosocial impairment, memory/reasoning deficits, and history of alcohol abuse have all been linked to poor work outcomes. An in-depth literature review by Chesnut et al. suggested that multiple issues besides cognitive and psychological factors, such as physical sequelae, impeded work [18]. Indeed, vocational specialists have known for some time that the array of different physical sequelae can be a problem for job retention [2,19].

Importantly, cognitive and behavioral sequelae after TBI significantly affect both RTW and employment stability. Executive function deficits are quite common with all TBI given the predisposition to frontal lobe injury. There is a strong correlation between self-awareness and favorable vocational outcome [3]. Furthermore, issues with depression, anger, and impaired social pragmatics negatively affect successful community reentry [6]. Given the complexity of the deficits commonly seen post-TBI and the myriad of psychosocial confounders that accompany these injuries, a holistic approach to vocational return is paramount. A full review of the cognitive and behavioral barriers is beyond the scope of this article and has been addressed in detail in other sources [2-3,6-7].

There is a critical need to examine the multiple physical and sensory sequelae associated with TBI. We were unable to locate a succinct review in the literature detailing these deficits and their effect on RTW. This article reviews the literature on these sequelae. We discuss how these sequelae affect RTW. In turn, suggestions based upon clinical practice are offered to guide the clinician's treatment approach. It is important to note that the subset of physical sequelae is related to the degree of TBI severity. For instance, seizures are much more common in moderate to severe than in mild TBI. These clinical groupings are-

- Mild TBI:

- Headaches.

- Vision deficits.

- Pain syndromes.

- Dizziness.

- Postural instability.

- Moderate to severe TBI:

- Heterotopic ossification.

- Hypertonicity.

- Seizures.

- Postural instability.

- Fine motor deficits.

- Visual deficits.

- Insomnia.

- Fatigue.

Hopefully, this article will improve TBI survivors' likelihood of successful vocational return.

\section{SEIZURES}

Posttraumatic seizures (or epilepsy) occurring after the first week following TBI affect 14 to 53 percent of survivors with moderate to severe TBI [20]. These seizures are extremely rare in individuals with mild TBI (or concussion). Although injury severity is predictive of seizures, the routine prophylaxis of patients with severe TBI has not been shown to be effective in reducing their late seizure risk [21]. In patients who will develop posttraumatic 
seizures, most have initial onset within 1 year postinjury and about 76 percent within 2 years [22-23]. A multicenter study found that among various TBI-related imaging abnormalities, seizures most often followed biparietal contusion, dural penetration with metal fragments, multiple intracranial surgeries, subdural hematoma with evacuation, midline shift $<5 \mathrm{~mm}$, and multiple or bilateral cortical contusions [24]. Other factors have also been identified, including chronic alcoholism, age, intracranial hemorrhage, length of posttraumatic amnesia, depressed skull fracture, lesion location, and early glucocorticoid administration [24-29]. Prophylaxis for late seizures longer than the universally recognized standard of 7 days postinjury in response to a perceived elevated risk, such as the above mentioned factors, warrants further investigation and is not at present recommended.

The development of late seizures warrants treatment. Complex partial seizures (acute altered cognition with focal motor or sensory abnormalities) are the most common presentation, followed by simple partial seizures (focal motor or sensory abnormalities with no change in cognition) and then generalized or tonic-clonic seizures. Absence seizures (brief periods of altered cognition) are rare following TBI. The use of carbamazepine for the management of partial seizures and valproate for generalized seizures is advocated $[20,30]$. Phenytoin and carbamazepine are sedating and may be detrimental to cognition and long-term neurological recovery [31]. Newer agents, while often less sedating and easier to use, are less studied specifically for TBI-related late seizures [31].

The presence of posttraumatic epilepsy after TBI may affect the ability of individuals to return to and maintain work or schooling [32-34]. This effect is rarely due to the actual seizure activity, which is typically managed with medications, but more often due to the side effects (somnolence, mild decline in alertness and attention) of the medications, the limitations prompted by the risk of seizures (e.g., unable to drive for 6 months after a seizure, unable to work at heights or with heavy machinery until seizure-free for 6-12 months), and the negative bias brought on by a seizure disorder. Efforts at work and school reintegration must be closely integrated with the clinicians treating these clients so that medication adjustments can be judiciously made, specific limitations can be understood and negotiated, and the entire team (patient, physician, vocational specialist) can work from the same knowledge base.

\section{SPASTICITY}

Spasticity collectively refers to a host of motor overactivity syndromes stemming from upper motor neuron damage [35]. While focusing on the impact of hypertonicity, the clinician must recognize the detrimental functional impact of the accompanying symptoms of upper motor neuron syndromes: weakness and the loss of dexterity. In combination, these symptoms impair muscular control and affect functional independence [36-40]. Spasticity can have positive, but more frequently negative, effects on patient function [41-42].

The unique presentations of spasticity and its functional impact warrant individualized treatment plans and serial clinical monitoring. Individual assessment is important, with particular attention paid to the spasticity distribution (upper vs lower, unilateral vs bilateral, global vs focal). After an injury to the cerebral motor strip, the upper limbs typically respond in a flexion pattern. Lower limbs are more often in extension, though this pattern is more variable [43]. Treatment of spasticity should be multimodal and include therapeutic interventions and medications. A detailed assessment of the distribution (focal vs global), severity, and functional impact is crucial [44].

For global spasticity, a variety of oral medications are employed, including dantrolene, tizanidine, diazepam, and baclofen [45-46]. Unfortunately, all may have the common adverse effect of sedation, which can be quite problematic in the work setting. Dantrolene has the least sedative effect given its primary action at the peripheral muscles, so it is widely considered the first-line agent [6]. Intrathecal delivery of baclofen offers a higher concentration delivered to the spinal cord with lower circulating drug levels, thereby minimizing systemic side effects. Multiple studies show that intrathecal baclofen is safe, effective, and well tolerated over time [47-50]. Injection techniques such as intramuscular phenol and botulinum toxin are effective in the treatment of focal spasticity. Botulinum toxin seems particularly effective in the upper limbs [51-52], especially when complemented with ongoing therapies to maximize functional improvements.

Employment can be therapeutic for persons with spasticity after TBI because of joint motion associated with body movements and by facilitating neural recovery and latent abilities. However, hypertonicity represents a significant barrier to successful vocational return, particularly when it involves the upper limbs. Reach, grasp, and fine motor control form the basis of many work settings. 
Furthermore, the other "negative" consequences (loss of dexterity and weakness) have additive detrimental effects. In combination, these decrease the radius of the workspace and have broad-ranging effects on efficiency and productivity. The lower-limb pattern can be somewhat beneficial and provide a stable base of support for standing. The increased energy expenditures with gait, though, must be taken into account.

A patient with spasticity should have a carefully tailored work space that takes into account his or her specific functional deficits. For those with significant upper-limb hypertonicity, the workspace area should be shortened to accommodate range of motion restrictions. Adaptive orthotics can assist in overcoming the deficits of grasp, discoordination, and hypertonicity. Particular emphasis should be placed upon the distribution because one side is commonly more affected. In this situation, tasks should be targeted to the preserved limb. Depending upon the pattern of lower-limb tone, appropriate seating modifications should be made. Further, it is important that the floor space be flat and free of impediments to allow for safe ambulation.

\section{HETEROTOPIC OSSIFICATION}

Heterotopic ossification (HO), or abnormal periarticular bone formation, occurs in 11 to 77 percent of individuals after TBI [53-57]. While the underlying pathophysiology of $\mathrm{HO}$ is unknown, a neuroendocrine alteration may be causative [58]. Risk factors for $\mathrm{HO}$ include prolonged coma (>2 months), ventilator support, spasticity, and fractures [59]. The symptoms of HO include pain, decreased range of motion, warmth, palpable mass, and tenderness [60]. The hips are overwhelmingly most affected, followed by the shoulders, knees, and elbows. Triple-phase bone scan allows early detection of $\mathrm{HO}$, whereas plain X-rays are useful for diagnosis only after calcification [61]. Serum alkaline phosphate may be used to monitor maturity of lesions but has limited utility in diagnosis [61]. Complications include decreased range of motion, frank joint ankylosis, pain, and nerve compression. Not surprisingly, HO has been linked to poorer functional outcomes [53,62].

Treatment of HO is geared toward the complication with the most functional impact: restriction of joint range. At the minimum, daily full range of motion exercise to prevent joint contractures is indicated [63]. The effects of pharmacologic treatment and prophylaxis of HO, includ- ing bisphosphates, nonsteroidal anti-inflammatory drugs (NSAIDs), and radiation, are controversial [57,64-66]. Surgical excision is employed when lesions are causing a barrier to function, though recurrence may occur regardless of its timing (early vs late excision) [58].

In the work setting, the joint range restrictions must be accommodated. As with spasticity, accommodation includes shrinking the space to allow for the decreased range of motion of the shoulders and elbows. The workspace should also be clear of clutter that may affect safe ambulation.

\section{POSTURAL INSTABILITY (BALANCE PROBLEMS)}

Balance problems are frequent after TBI. Early balance deficits after severe TBI can indicate poorer long-term functional recovery [67-68] and can persist chronically. One study of severe TBI showed 34 percent of survivors with severe TBI reported balance impairments at 5 years [69]. In another study, 29 percent tested abnormal on tandem gait at 2 years [70]. TBI-related balance impairments are not exclusive to severe injuries. Investigations using computerized posturography testing (CPT) show that balance deficits are present acutely after mild TBI (e.g., concussion) [7172]. Published data on balance deficits is lacking within the late postconcussive syndrome population.

Objective methods for quantifying balance impairment after TBI (CPT) can aid both the tracking of mobility recovery and the formulation of recommendations for disability, job restrictions, and leisure activities. CPT also provides data about the pattern of postural instability, which may be useful in guiding rehabilitation interventions [73]. More traditional quantitative balance tests include variations of the Romberg test [74], the test of sway [75], and the Berg Balance Scale [76].

Balance problems are important because of their potential impact on both basic (transfers, walking, etc.) and high-level (jumping, climbing, running, etc.) mobility skills. Even when grossly "independent," most individuals need some degree of high-level mobility skills for a complete and safe return to leisure and/or vocational activities. Safety risks from balance impairment are dramatically worsened when cognitive impairment coexists, which is common after severe TBI. Subsequently, individuals do not recognize physical limitations and fail to incorporate constructive strategies to safely compensate for their balance deficit. 
Evaluation of patients with imbalance after TBI should include assessment for peripheral neuropathy, postural hypotension, limb ataxia, visual impairment, and dizziness symptoms. Patients with moderate or severe TBI should undergo a formal balance assessment, ideally with CPT, before returning to select work duties, military training, or combat. From a vocational rehabilitation standpoint, working at heights, on platforms, or around moving or sharp machinery is contraindicated in the presence of significant postural instability.

Despite the frequency of postural instability after TBI, scant published research addresses the effectiveness of interventions. Traditional approaches include physical therapy for specific exercises to promote postural stability, such as joint approximation, alternating isometrics, rhythmic stabilization, and practice of controlled mobility activities and functional movement transitions [77]. Biofeedback instruments can be added, such as a force platform or CPT. Individuals with falls or near falls while ambulating should also use a gait aid, especially on uneven terrain.

\section{DIZZINESS}

Posttraumatic dizziness affects 20 to 65 percent of patients with TBI [67,78-79] and remains disabling for many months [8,80-82]. Dizziness is among the top five postconcussive symptoms distinguishing patients with mild TBI from healthy controls [79,83-84] and appears to have important vocational implications. One study showed a 46 percent failure of RTW 5 years after mild to moderate TBI for patients with posttraumatic dizziness. A more recent study on RTW at 6 months postinjury (mild and moderate) showed 34 percent of individuals with dizziness were gainfully employed compared with nearly 75 percent of subjects without dizziness. Importantly, dizziness was also associated with increased psychological distress (including anxiety and depression), which may further hinder RTW efforts [85].

Studies of patients with dizziness after mild to moderate TBI show a rate of vestibular abnormalities of between 32 and 65 percent [86-87]. The large number of patients with dizziness who do not have objective findings of neural damage reinforces the connection with psychological factors [85-86]. Medication-based treatments, such as the anxiolytic agents buspirone or trazodone, may be aimed at these psychological factors and can have positive effects on symptoms. Commonly prescribed "sedat- ing" medications, such as meclizine, are controversial in that their mechanism of decreasing the sensation of causative stimuli can theoretically slow recovery. Focused vestibular rehabilitation programs with purposeful exposure, habituation, and coping strategies have proven efficacy [87]. Benign paroxysmal positional vertigo is a condition that is caused by movement of otolithic debris or granules within the semicircular canals. Trauma can lead to the release of such debris. Specific therapies (Dix-Hallpike maneuver and Liberatory technique) can be used for both diagnosis and therapy [68].

Even in the face of disabling dizziness, progressive return to activity, including driving and work, is key to both reducing symptoms and preventing habituation to abnormal movement patterns (e.g., remaining lying down for activities). This "forced" activity is a necessary component of the rehabilitation efforts for vertigo. Intensive vocational rehabilitation services are indicated and invaluable in the early rehabilitation course $[11,88]$. Work site modifications and job accommodations are initially an integral aspect of vocational rehabilitation, but can usually be tapered away as the symptoms and tolerance improve. Gradated exposure to the necessary aspects of the job (e.g., repeated movements, visual distractions) is both therapeutic and facilitates RTW efforts. Medications, while occasionally helpful early in the treatment program, are limited in the work setting because of cognitive depression.

\section{FINE MOTOR DEFICITS}

Gross motor deficits do not occur after uncomplicated mild TBI and seldom persist chronically after severe TBI. One report showed hemiparesis in 15 percent and quadraparesis in 6 percent 5 years after severe TBI [69]. A more recent report showed arm weakness in 13 percent and leg weakness in 9 percent 2 years after inpatient rehabilitation [70].

Motor integrative function and fine motor skills are more common persisting deficits after TBI and often have occult presentations. Various investigations have shown impairment in finger tapping 1 year after mild to moderate TBI [89]; impairment in integrative gross motor and speeded fine motor skills 16 months after severe TBI [90]; deficits in fine motor skills, speed, and coordination 8 months after TBI [91]; subclinical bradykinesia with impaired complex and simple reaction time 1 year after TBI [92]; residual motor programming deficits in severe chronic 
TBI despite clinically good motor recovery [93]; and selective deficit in motor preparation in severe TBI with good clinical recovery [94]. The grooved pegboard (GPB) test is a fine motor test included in many standard comprehensive neuropsychological batteries after TBI. In a large severeTBI cohort, GPB was more commonly impaired than any of the predominantly cognitive performance tests at 5 years post-TBI, with 75 percent scoring under the 16th percentile for age-matched norms [95].

Fine motor impairment after TBI has important functional implications. Slower speed on the GPB is associated with poorer vocational outcome [96] and poorer Glasgow Outcome Scale scores [97]. From a vocational reentry standpoint, fine motor speed and dexterity should be formally assessed with appropriate modifications or restrictions for any tasks requiring high levels of fine motor functioning. Ideally, the tasks themselves should be directly assessed for speed and performance errors. Patients with deficits may also benefit from specific rehabilitation interventions. A recent evidence-based review article found "moderate" evidence to support the use of functional fine motor control retraining to improve motor coordination after acquired brain injury [98].

\section{VISION}

Reports of visual changes (usually worsened visual acuity) occur in up to 20 to 40 percent of individuals with TBI $[69,99]$. True deficits in vision are difficult to differentiate from visual perceptual deficits (the brain's interpretation of what the eyes see) [99]. True field cuts (e.g., homonymous hemianopsia, quadrantonopsia, tunnel vision) are more common in ischemic damage to the brain but may also be seen with traumatic injuries [100-101]. Cortical blindness (Anton's syndrome) may be seen following occipital lobe injury but is uncommon [102]. The Useful Field of View (UFOV) test is a measure of the functional or useful range of peripheral vision under cognitive load conditions [103]. As cognitive load is increased by elevating task complexity, the functional range of peripheral vision (i.e., the degree of peripheral vision from which information is processed) becomes restricted [104]. Thus, the functional extent of peripheral vision under complex real-world conditions, such as detecting stimuli in cluttered backgrounds, is not always equivalent to the maximum extent of peripheral vision that can be measured with clinical perimetry techniques [105]. Individuals with TBI and strokes and older adults often have impaired UFOV [105-107]. Survivors with TBI exhibited decreased information processing time and mild impairment at all eccentricities, with the greatest impairment on the selective attention subtest of the UFOV. These findings suggest that survivors with TBI may need more time to locate stimuli in cluttered backgrounds and are less accurate than people without brain impairment. These results are consistent with previous reports of higher errors and task completion times on cancellation tests involving visual search [106].

Rehabilitation efforts for visual deficits focus on enriching the environments to increase appropriate stimuli to the areas of visual decline. This strategy should be applied both in the structured therapy setting and in the general treatment milieu. While a variety of specific visual rehabilitation programs have been described [100-101], there is no universal agreement on the efficacy of these protocols. In addition to enhancing visual stimuli and specialized interventions, rehabilitation efforts must also focus on enhancing the cognitive functioning. The use of these strategies and devices allows for greater adaptation to deficits and greater use of other senses. Many of the tactics used for newly blind individuals (from any cause) are used in a modified way for individuals with TBI.

Studies have demonstrated poorer overall functional outcomes with persistent visual deficits $[69,106,108]$ and poorer RTW with visual perceptual deficits after TBI [109]. Vocational efforts for individuals who have visual deficits that are of clinical significance are typically introduced once an individual has returned to the community. Transportation to the work site may present significant challenges and must be addressed early in the course. Unique aspects of "blind rehabilitation" that are relevant to the individual with TBI are the overlying cognitive, behavioral, and physical impairments commonly seen. Safety concerns must be emphasized in individuals with TBI and impaired sight because of the decreased sensory feedback and, not uncommonly, decreased safety judgment.

\section{HEADACHES AND PAIN}

Pain is commonplace after TBI of all severity levels. In a study of hospitalized patients with TBI, 71 percent required narcotic pain medication prescription upon discharge [110]. In an adult tertiary care pain clinic investigation, 58 percent of persons with mild and 52 percent with moderate to severe TBI reported chronic pain [111]. 
Chronic pain is usually defined as 6 contiguous months of pain and is often intertwined with psychopathology and environmental factors [112]. In its persistent form, chronic pain typically imposes severe emotional, physical, economic, and social stresses on the patient and family.

After major trauma, potential etiologies of pain are numerous. The anatomical source of pain in individuals after TBI may be intracranial or extracranial, depending on the pattern of trauma [113]. Proper detection and diagnosis of pain is paramount for achieving optimal rehabilitation potential after TBI. With proper evaluation, pain can often be classified into one of the following clinical types: musculoskeletal, vascular, visceral, or neural tissue origin.

Headache (HA) is the most frequent pain reported after TBI, with a prevalence range from 18 to 93 percent depending on study methodologies [114]. HA that commences within 14 days of consciousness following TBI is termed posttraumatic HA (PTHA) [115]. Some investigations show higher prevalence of PTHA in milder TBI [111,116-118], but this finding remains controversial given sample selection bias concerns and conflicting reports [119-120]. PTHA is usually self-limited but may become chronic. A longitudinal study of patients with moderate and severe TBI showed daily PTHA in 30 percent during inpatient rehabilitation, declining to 10 percent 6 months later [120]. Similar to chronic pain in the general population, the evolution from acute to chronic PTHA is linked to emotional distress [119-120]. Chronic PTHA that persists beyond 6 months after injury will usually become permanent and disabling [120-122].

There is a shortage of treatment trials in PTHA to offer standard of care guidance for clinicians [123]. Clinicians should, after excluding serious intracranial pathology, attempt to classify PTHA and use medical treatment accordingly. Migraine HA type, diagnosed in 26 percent of one PTHA sample [120], appears to be overrepresented compared with its distribution in the general population [124]. Migraine-specific HA medications should be trialed for migraine-type PTHA. Cervicogenic HA, originating from cervical spine or surrounding soft tissues, is common after TBI [114] and may respond to physical therapy and modalities. PTHA with neuropathic quality may respond to neuropathic pain medications or peripheral nerve blocks. Narcotic medications and other medications with central effects such as muscle relaxants should be avoided if possible. Tension and cervicogenic HA may respond to NSAIDs and/or acetaminophen. Concomitant emotional disorders such as depression and anxiety should be treated with appropriate pharmacological and behavioral treatments. Even absent emotional disorders, psychological evaluation and behavior therapy, including relaxation training or biofeedback, may be beneficial. Contributing factors should also be sought out, including sleep disturbances, excessive caffeine intake, and sources of emotional distress.

From a vocational rehabilitation standpoint, the role of emotional stress in PTHA is paramount. Patients should be monitored for the onset of delayed PTHA or exacerbation of preexisting PTHA during work reentry or after changes in work routine. Whenever PTHA or other chronic pain syndromes worsen in employed patients with TBI, they should be medically examined. Their work schedule and duties should as well be reevaluated. Some PTHA syndromes (migraine) may be episodically disabling and necessitate intermittent work absence. Others may be chronically disabling (chronic daily HA), causing total work disability if refractory to treatment.

\section{INSOMNIA}

Insomnia following TBI is a common condition that requires close attention. Its effects on overall function and quality of life are well documented [125-128]. Following a TBI, 30 to 70 percent of survivors report difficulties with sleep [125,128-136]. In two separate studies, nearly 30 percent of TBI survivors met Diagnostic and Statistical Manual of Mental Disorders, Fourth Edition, criteria for insomnia syndrome [125,132]. In comparison, this rate is three times greater than the general population [137-138]. The most common features of TBI-related insomnia are sleep initiation and maintenance problems $[125,139]$. While some literature suggests the volume of sleep complaints decreases over time [130-131,134], the data suggest that a significant proportion develop a chronic course [130,136,140].

The literature on risk factors associated with post-TBI insomnia is scant $[125,128]$. Older age, female gender, depression, HAs, and alcohol abuse were negative prognosticators in one study [129]. Others show a similar association with depression, as well as less severe injuries $[129,132]$. Conversely, those with successful vocational return had less difficulty sleeping [129]. Given the limited information available, more research is needed to better understand the impact of other factors, including pain [141], psychological distress, and fatigue, on sleep after TBI. 
Treatment of post-TBI insomnia is multifaceted, including sleep hygiene education, cognitive-behavioral therapy, and pharmacology. Behavioral approaches are more time-consuming but have been shown to produce more effective long-term results than use of medications alone [142]. Medications that promote the initiation and maintenance of sleep fall into four categories: benzodiazepine sedative hypnotics (diazepam, lorazepam), nonbenzodiazepine sedative hypnotics (zolipidem, etc.), antidepressants (trazodone, mirtazapine), and neutraceuticals (melatonin). These medications have all been shown to promote healthy sleep in the short-term, but effects of longterm use are poorly documented and the side effect profiles may be more problematic in the population with TBI. The benzodiazepines have a prominent hangover effect manifested by cognitive suppression and psychomotor agitation, and chemical dependency may occur [143-145]. The antidepressants are better tolerated but may carry anticholinergic and cardiac risks [146-151]. The nonbenzodiazepine sedatives carry the lowest side effect profile while maintaining similar efficacy on sleep parameters [128,152-160]. Further studies in the population with TBI are warranted to determine the most efficacious agents.

When assessing patients with TBI, clinicians must continuously evaluate sleep patterns and daytime symptoms and pay close attention to daytime fatigue, HAs, and irritability. Insomnia leads to daytime fatigue, confusion, HAs, exacerbation of pain, and mood alterations [126-127]. These symptoms and side effects from pharmacological treatment compound the cognitive and behavioral changes associated with TBI. The impact of insomnia on work can be profound. Though challenging, reestablishing healthy and restorative sleep patterns after TBI is fundamental to the return of quality of life and vocational success.

\section{FATIGUE}

Fatigue is commonly observed and reported after TBI, regardless of severity. Following HAs and dizziness, it is the third most prevalent symptom of postconcussive syndrome [83,161-162]. Studies on fatigue in the general population have documented prevalence rates ranging from 7 to 45 percent [163]. The wide range of prevalence rates is likely attributable to differences in operationalizing a working definition of fatigue, as well as the variability of fatigue across different medical conditions and interventions. Some researchers have argued in favor of a multidimensional approach, such as defining fatigue in the dimensions of general, physical, and mental fatigue [163]. Typically, an assessment of fatigue is obtained via a detailed history [134], a structured interview [164], or questionnaires designed to measure broader conditions (e.g., Beck Depression Inventory) [165]. The most commonly recognized questionnaires in the literature are the Fatigue Impact Scale [164], the Fatigue Severity Scale [166], and the Barrow Neurologic Institute Fatigue Scale [167].

While fatigue is often clinically observed in braininjured patients during the acute stages of recovery, there is a dearth of empirical studies on this topic. Fatigue has been shown to be a clinically relevant symptom up to 10 years postinjury [134,168-169], the Fatigue, both physical and mental, has been demonstrated to negatively affect functional performance [134,161,170-171] and return to vocational efforts [109,172]. Treatments focus on managing underlying physical (endocrine, infectious, cardiovascular) and psychological (depression, stress) factors and use of neurostimulant agents (e.g., methylphenidate) [83].

Vocational interventions need to address physical and cognitive conditioning to allow for successful employment. In addition, work accommodations should be made to account for decrease in functional abilities. As with many posttraumatic symptoms, a progressive program of reactivation of the body and the mind is both a specific treatment of the underlying symptom and a necessary vocational rehabilitation intervention. While scheduled rest breaks, adjusted work schedules, and job modifications may be needed initially to maintain the client in a vocational situation, the long-term goal is one of gradual weaning away of these adjustments. The partnership between the medical and rehabilitation team and the vocational specialist is vital to facilitate rapid feedback of the successes of interventions and the potential exacerbation of symptoms related to work.

\section{CONCLUSIONS}

The sequelae described in this article represent challenges to successful RTW. These problems are recurrent and long-term and clearly affect job procurement, nature of job, level of required support, and likelihood of job retention. Conversely, these challenges should not be viewed as impenetrable obstacles. With appropriate supports, such as compensatory strategies, job coaching, assistive technology, medical management, and job restructuring, successful RTW is a viable option. Most of the sequelae described 
MCNAMEE et al. TBI sequelae and vocational return

have solutions, not the least of which is searching for a more appropriate job. The astute medical professional will focus repeatedly on two questions:

- When will my patient be employed?

- What supports are needed for my patient to become employed?

The limitations faced by many patients with TBI can best be overcome through clever job search, job redesign, and community linkages with business and industry that are willing to partner in helping the patient with TBI regain employment. For example, the person who has periodic HAs may fair poorly in a stimulus-rich environment and flourish in a more controlled environment. The physician plays a key role in communicating suggestions to the vocational specialist.

Community rehabilitation programs (CRPs) provide supported employment services, frequently through agreements with state vocational rehabilitation agencies. The CRP staff members that provide employment services are called employment specialists. Well-trained employment specialists are skilled in a variety of activities necessary to identify, develop, implement, and monitor individualized employment supports.

Physicians must focus on employment outcomes in real jobs and not settle for volunteer work, sheltered work, or assessment and planning. Individuals should be placed in real work for real pay. Through close collaboration between the survivor of TBI, physician, vocational specialist, and community resources, successful employment for survivors with TBI is possible and must be assigned a high value.

\section{ACKNOWLEDGMENTS}

\section{Author Contributions:}

Study concept and design: S. McNamee, W. Walker, D. X. Cifu, P. H. Wehman.

Drafting of manuscript: S. McNamee, W. Walker, D. X. Cifu,

P. H. Wehman.

Critical revision of manuscript for important intellectual content:

S. McNamee.

Administrative, technical, or material support: S. McNamee.

Financial Disclosures: The authors have declared that no competing interests exist.

Funding/Support: This material was unfunded at the time of manuscript publication.

\section{REFERENCES}

1. Thurman DJ, Alverson C, Dunn KA, Guerrero J, Sniezek JE. Traumatic brain injury in the United States: A public health perspective. J Head Trauma Rehabil. 1999;14(6): 602-15. [PMID: 10671706]

DOI:10.1097/00001199-199912000-00009

2. Wehman P, Kreutzer JS, Sale P, West M, Morton MV, Diambra J. Cognitive impairment and remediation: Implications for employment following traumatic brain injury. J Head Trauma Rehabil. 1989;4(3):66-75. DOI:10.1097/00001199-198909000-00010

3. Shames J, Treger, I, Ring H, Giaquinto S. Return to work following traumatic brain injury: Trends and challenges. Disabil Rehabil. 2007;29(17):1387-95. [PMID: 17729084]

4. Partridge TM. An investigation into the vocational rehabilitation practices provided by brain injury services throughout the United Kingdom. Work. 1997;7(1):63-72.

5. Pettifer S. Leisure as compensation for employment and unfulfilling work: Reality or pipedream. J Occup Sci. 1993; 1(2):20-28.

6. Cifu DX, Kreutzer JS, Slater D, Taylor L. Issues in brain injury rehabilitation. In: Braddom RL, editor. Physical medicine and rehabilitation. 3rd ed. Philadelphia (PA): Saunders Elsevier; 2007. p. 1133-74.

7. McMordie WR, Barker SL, Paolo TM. Return to work (RTW) after head injury. Brain Inj. 1990;4(1):57-69. [PMID: 2297601] DOI:10.3109/02699059009026149

8. Van der Naalt J, Van Zomeren AH, Sluiter WJ, Minderhoud JM. One year outcome in mild to moderate head injury: The predictive value of acute injury characteristics related to complaints and return to work. J Neurol Neurosurg Psychiatry. 1999;66(2):207-13. [PMID: 10071101] DOI:10.1136/jnnp.66.2.207

9. Cifu DX, Craig EJ, Rowland T. Neuromedical considerations affecting return to work in the brain injured adult. J Vocational Rehabil. 1999;7(3):257-65.

10. Wehman P, Kreutzer JS, West M, Sherron P, Diambra J, Fry R, Groah C, Sale P, Killam S. Employment outcomes of persons following traumatic brain injury: Pre-injury, post-injury, and supported employment. Brain Inj. 1989; 3(4):397-412. [PMID: 2819319] DOI:10.3109/02699058909004563

11. Yasuda S, Wehman P, Targett P, Cifu D, West M. Return to work for persons with traumatic brain injury. Am J Phys Med Rehabil. 2001;80(11):852-64. [PMID: 11805460] DOI:10.1097/00002060-200111000-00011

12. Brooks N, Campsie L, Symington C, Beattie A, McKinlay $\mathrm{W}$. The effects of severe head injury on patient and relative within seven years of injury. J Head Trauma Rehabil. 1987;2(3):1-13. DOI:10.1097/00001199-198709000-00003

13. Rao N, Rosenthal M, Cronin-Stubbs D, Lambert R, Barnes P, Swanson B. Return to work after rehabilitation following traumatic brain injury. Brain Inj. 1990;4(1):49-56. 
[PMID: 2297600]

DOI: $10.3109 / 02699059009026148$

14. Dikmen SS, Temkin NR, Machamer JE, Holubkov AL, Fraser RT, Winn HR. Employment following traumatic head injuries. Arch Neurol. 1994;51(2):177-86.

[PMID: 8304843]

15. Gollaher K, High W, Sherer M, Bergloff P, Boake C, Young ME, Ivanhoe C. Prediction of employment outcome one to three years following traumatic brain injury (TBI). Brain Inj. 1998;12(4):255-63. [PMID: 9562908] DOI:10.1080/026990598122557

16. Ip RY, Dornan J, Schentag C. Traumatic brain injury: Factors predicting return to work or school. Brain Inj. 1995; 9(5):517-32. [PMID: 7550223] DOI:10.3109/02699059509008211

17. Sander AM, Krentzer JS, Rosenthal M, Delmonico R, Young ME. A multicenter longitudinal investigation of return to work and community integration following traumatic brain injury. J Head Trauma Rehabil. 1996;11(5): 70-84. DOI:10.1097/00001199-199610000-00007

18. Chesnut RM, Carney N, Maynard H, Mann NC, Patterson P, Helfand M. Summary report: Evidence for the effectiveness of rehabilitation for persons with traumatic brain injury. J Head Trauma Rehabil. 1999;14(2):176-88.

[PMID: 10191375]

DOI:10.1097/00001199-199904000-00007

19. Walker WC, Marwitz JH, Kreutzer JS, Hart T, Novack TA. Occupational categories and return to work after traumatic brain injury: A multicenter study. Arch Phys Med Rehabil. 2006;87(12):1576-82. [PMID: 17141636] DOI:10.1016/j.apmr.2006.08.335

20. Yablon SA. Posttraumatic seizures. Arch Phys Med Rehabil. 1993;74(9):983-1001. [PMID: 8379848]

21. Temkin NR, Dikmen SS, Wilensky AJ, Keihm J, Chabal S, Winn HR. A randomized, double-blind study of phenytoin for the prevention of post-traumatic seizures. N Engl J Med. 1990;323(8):497-502. [PMID: 2115976]

22. Hauser WA, Annegers JF, Kurland LT. Prevalence of epilepsy in Rochester, Minnesota: 1940-1980. Epilepsia. 1991; 32(4):429-45. [PMID: 1868801]

DOI:10.1111/j.1528-1157.1991.tb04675.x

23. Walker AE, Jablon S. A follow-up of head-injured men of World War II. J Neurosurg. 1959;16(6):600-10.

DOI:10.3171/jns.1959.16.6.0600

24. Englander J, Bushnik T, Duong TT, Cifu DX, Zafonte R, Wright J, Hughes R, Bergman W. Analyzing risk factors for late posttraumatic seizures: A prospective, multicenter investigation. Arch Phys Med Rehabil. 2003;84(3):365-73. [PMID: 12638104]

DOI:10.1053/apmr.2003.50022

25. Annegers JF, Grabow JD, Groover RV, Laws ER Jr, Elveback LR, Kurland LT. Seizures after head trauma: A popu- lation study. Neurology. 1980;30(7 Pt 1):683-89. [PMID: 7190235]

26. Evans JH. Post-traumatic epilepsy. Neurology. 1962;12: 665-74. [PMID: 13890989]

27. Grafman J, Jonas B, Salazar A. Epilepsy following penetrating head injury to the frontal lobes. Effects on cognition. Adv Neurol. 1992;57:369-78. [PMID: 1543066]

28. Kollevold T. Immediate and early cerebral seizures after head injuries: Part III. J Oslo City Hosp. 1978;28(6):78-86. [PMID: 96238]

29. Watson NF, Barber JK, Doherty MJ, Miller JW, Temkin NR. Does glucocorticoid administration prevent late seizures after head injury? Epilepsia. 2004;45(6):690-94. [PMID: 15144437] DOI:10.1111/j.0013-9580.2004.59403.x

30. D’Ambrosio RA, Perucca EB. Epilepsy after head injury. Curr Opin Neurol. 2004;17(6):731-35. DOI:10.1097/00019052-200412000-00014

31. Dodrill CB, Troupin AS. Neuropsychological effects of carbamazepine and phenytoin: A reanalysis. Neurology. 1991;41(1):141-43. [PMID: 1985279]

32. Nybo T, Sainio M, Müller K. Stability of vocational outcome in adulthood after moderate to severe preschool brain injury. J Int Neuropsychol Soc. 2004;10(5):719-23. [PMID: 15327719] DOI:10.1017/S1355617704105109

33. Johnstone B, Martin TA, Bounds TA, Brown E, Rupright J, Sherman A. The impact of concomitant disabilities on employment outcomes for state vocational rehabilitation clients with traumatic brain injury. J Voc Rehabil. 2006; 25(2):97-105.

34. Mount D, Johnstone B, White C, Sherman A. Vocational outcomes: VR service determinants for persons with epilepsy. J Voc Rehabil. 2005;23(1):11-20.

35. Crooks CY, Zumsteg JM, Bell KR. Traumatic brain injury: A review of practice management and recent advances. Phys Med Rehabil Clin N Am. 2007;18(4):681-710. [PMID: 17967360] DOI:10.1016/j.pmr.2007.06.005

36. Lance JW. Pyramidal and extrapyramidal disorders. In: Shahani DT, editor. Electromyography in CNS disorders: Central EMG. Boston (MA): Butterworth; 1984. p. 1-19.

37. Lance JW. Symposium synopsis. In: Feldman RG, Young RR, Koella WP, editors. Spasticity: Disordered motor control. Chicago (IL): Yearbook Medical; 1980. p. 485-94.

38. Burke D. Spasticity as an adaptation to pyramidal tract injury. Adv Neurol. 1988;47:401-23. [PMID: 3278524]

39. Katz RT, Rymer WZ. Spastic hypertonia: Mechanisms and measurement. Arch Phys Med Rehabil. 1989;70(2): 144-55. [PMID: 2644919]

40. Pierrot-Deseilligny DE, Maziers L. Spinal mechanisms underlying spasticity. In: Delwaide PJ, Young RR, editors. 
Clinical neurophysiology in spasticity. New York (NY): Elsevier; 1985. p. 63-76.

41. Yarkony GM, Sahgal V. Contractures. A major complication of craniocerebral trauma. Clin Orthop Relat Res. 1987;(219):93-96. [PMID: 3581588]

42. Harburn KL, Potter PJ. Spasticity and contractures. In: Teasell RW, editor. State of the art reviews: Physical medicine and rehabilitation. Vol. 8. Philadelphia (PA): Hanley \& Belfus; 1993.

43. Mayer NH, Esquenazi A, Childers MK. Common patterns of clinical motor dysfunction. Muscle Nerve Suppl. 1997;6: S21-35. [PMID: 9826981] DOI:10.1002/(SICI)1097-4598(1997)6+<21::AID-MUS4 >3.0.CO;2-L

44. Wilson DJ, Swaboda JL. Partial weight-bearing gait retraining for persons following traumatic brain injury: Preliminary report and proposed assessment scale. Brain Inj. 2002;16(3):259-68. [PMID: 11874617] DOI:10.1080/02699050110103922

45. Meythaler JM, Guin-Renfroe S, Johnson A, Brunner RM. Prospective assessment of tizanidine for spasticity due to acquired brain injury. Arch Phys Med Rehabil. 2001; 82(9):1155-63. [PMID: 11552184]

DOI:10.1053/apmr.2001.25141

46. Meythaler JM, Clayton W, Davis LK, Guin-Renfroe S, Brunner RC. Orally delivered baclofen to control spastic hypertonia in acquired brain injury. J Head Trauma Rehabil. 2004;19(2):101-8. [PMID: 15247821]

DOI:10.1097/00001199-200403000-00003

47. Meythaler JM, Guin-Renfroe S, Grabb P, Hadley MN. Long-term continuously infused intrathecal baclofen for spastic-dystonic hypertonia in traumatic brain injury: 1-year experience. Arch Phys Med Rehabil. 1999;80:13-19.

[PMID: 9915366] DOI:10.1016/S0003-9993(99)90301-5

Erratum in: Arch Phys Med Rehabil. 1999;80(4):474.

48. Meythaler JM, Guin-Renfroe S, Hadley MN. Continuously infused intrathecal baclofen for spastic/dystonic hemiplegia: A preliminary report. Am Phys Med Rehabil. 1999;78(3):247-54. [PMID: 10340423]

DOI:10.1097/00002060-199905000-00012

49. Rawicki B. Treatment of cerebral origin spasticity with continuous intrathecal baclofen delivered via an implantable pump: Long-term follow-up review of 18 patients. J Neurosurg. 1999;91(5):733-36. [PMID: 10541228] DOI:10.3171/jns.1999.91.5.0733

50. François B, Vacher P, Roustan J, Salle JY, Vidal J, Moreau JJ, Vignon P. Intrathecal baclofen after traumatic brain injury: Early treatment using a new technique to prevent spasticity. J Trauma. 2001;50(1):158-61. [PMID: 11231690] DOI:10.1097/00005373-200101000-00035

51. Pavesi G, Brianti R, Medici D, Mammi P, Mazzucchi A, Mancia D. Botulinum toxin type A in the treatment of upper limb spasticity among patients with traumatic brain injury. J Neurol Neurosurg Psychiatry. 1998;64(3):419-20. [PMID: 9527178]

DOI:10.1136/jnnp.64.3.419

52. Francisco GE, Boake C, Vaughn A. Botulinum toxin in upper limb spasticity after acquired brain injury: A randomized trial comparing dilution techniques. Am J Phys Med Rehabil. 2002;81(5):355-63. [PMID: 11964576] DOI:10.1097/00002060-200205000-00007

53. Johns JS, Cifu DX, Keyser-Marcus L, Jolles PR, Fratkin MJ. Impact of clinically significant heterotopic ossification on functional outcome after traumatic brain injury. J Head Trauma Rehabil. 1999;14(3):269-76. [PMID: 10381979] DOI:10.1097/00001199-199906000-00007

54. Burnett DM, Watanabe TK, Greenwald BD. Congenital and acquired brain injury. 2. Brain injury rehabilitation: Medical management. Arch Phys Med Rehabil. 2003; 84(3 Suppl 1):S8-S11. [PMID: 12708552]

55. Flin C, Curalucci H, Duvocelle A, Viton JM. Heterotopic ossification and brain injury. Ann Readapt Med Phys. 2002;45(9):517-20. (French). [PMID: 12495825] DOI:10.1016/S0168-6054(02)00305-7

56. Garland DE, Blum CE, Waters RL. Periarticular heterotopic ossification in head-injured adults. Incidence and location. J Bone Joint Surg Am. 1980;62(7):1143-46. [PMID: 6776126]

57. Garland DE. A clinical perspective on common forms of acquired heterotopic ossification. Clin Orthop Relat Res 1991;263:13-29. [PMID: 1899635]

58. Chalidis B, Stengel D, Giannoudis PV. Early excision and late excision of heterotopic ossification after traumatic brain injury are equivalent: A systematic review of the literature. J Neurotrauma. 2007;24(11):1675-86. [PMID: 18001198] DOI:10.1089/neu.2007.0342

59. Pape HC, Marsh S, Morley JR, Krettek C, Giannoudis PV. Current concepts in the development of heterotopic ossification. J Bone Joint Surg Br. 2004;86(6):783-87. [PMID: 15330014] DOI:10.1302/0301-620X.86B6.15356

60. Jensen LL, Halar E, Little JW, Brooke MM. Special review: Neurogenic heterotopic ossification. Am J Phys Med. 1988;66:351-63.

61. Orzel JA, Rudd TG. Heterotopic bone formation: Clinical, laboratory, and imaging correlation. J Nucl Med. 1985;26(2):125-32. [PMID: 3918147]

62. Ebinger T, Roesch M, Kiefer H, Kinzl L, Schulte M. Influence of etiology in heterotopic bone formation of the hip. J Trauma. 2000;48(6):1058-62. [PMID: 10866251] DOI:10.1097/00005373-200006000-00010

63. Linan E, O'Dell MW, Pierce JM. Continuous passive motion in the management of heterotopic ossification in a brain injured patient. Am J Phys Med Rehabil. 2001; 
80(8):614-17. [PMID: 11475483]

DOI:10.1097/00002060-200108000-00013

64. Jang SH, Shin SW, Ahn SH, Cho IH, Kim SH. Radiation therapy for heterotopic ossification in a patient with traumatic brain injury. Yonsei Med J. 2000;41(4):536-39. [PMID: 10992819]

65. Sazbon L, Najenson T, Tartakovsky M, Becker E, Grosswater $\mathrm{Z}$. Widespread periarticular new-bone formation in long-term comatose patients. J Bone Joint Surg Br. 1981; 63-B(1):120-25. [PMID: 7204466]

66. Balboni TA, Gobezie R, Mamon HJ. Heterotopic ossification: Pathophysiology, clinical features, and the role of radiotherapy for prophylaxis. Int J Radiat Oncol Biol Phys. 2006;65(5):1289-99. [PMID: 16863921] DOI:10.1016/j.ijrobp.2006.03.053

67. Duong TT, Englander J, Wright J, Cifu DX, Greenwald BD, Brown AW. Relationship between strength, balance, and swallowing deficits and outcome after traumatic brain injury: A multicenter analysis. Arch Phys Med Rehabil. 2004;85(8):1291-97. [PMID: 15295755]

DOI:10.1016/j.apmr.2003.11.032

68. Greenwald BD, Cifu DX, Marwitz JH, Enders LJ, Brown AW, Englander JS, Zafonte RD. Factors associated with balance deficits on admission to rehabilitation after traumatic brain injury: A multicenter analysis. J Head Trauma Rehabil. 2001;16(3):238-52. [PMID: 11346446] DOI:10.1097/00001199-200106000-00003

69. Hillier SL, Sharpe MH, Metzer J. Outcomes 5 years posttraumatic brain injury (with further reference to neurophysical impairment and disability). Brain Inj. 1997; 11(9):661-75. [PMID: 9376834] DOI:10.1080/026990597123214

70. Walker WC, Pickett TC. Motor impairment after severe traumatic brain injury: A longitudinal multicenter study. J Rehabil Res Dev. 2007;44(7):975-82. [PMID: 18075954] DOI:10.1682/JRRD.2006.12.0158

71. Guskiewicz KM. Assessment of postural stability following sport-related concussion. Curr Sports Med Rep. 2003; 2(1):24-30. [PMID: 12831673]

72. Guskiewicz KM, Ross SE, Marshall SW. Postural stability and neuropsychological deficits after concussion in collegiate athletes. J Athl Train. 2001;36(3):263-73. [PMID: 12937495]

73. Pickett TC, Radfar-Baublitz LS, McDonald SD, Walker WC, Cifu DX. Objectively assessing balance deficits after TBI: Role of computerized posturography. J Rehabil Res Dev. 2007;44(7):983-90. [PMID: 18075955] DOI:10.1682/JRRD.2007.01.0001

74. Ingersoll CD, Armstrong CW. The effects of closed-head injury on postural sway. Med Sci Sports Exerc. 1992; 24(7):739-43. [PMID: 1501556] DOI:10.1249/00005768-199207000-00001
75. Lehman JF, Boswell S, Price R, Burleigh A, DeLateur BJ, Jaffe KM, Hertling D. Quantitative evaluation of sway as an indicator of functional balance in post-traumatic brain injury. Arch Phys Med Rehabil. 1990;71(12):955-62. [PMID: 2241541]

76. Berg KO, Wood-Dauphinee SL, Williams JI, Maki B. Measuring balance in the elderly: Validation of an instrument. Can J Pub Health. 1992;83(Suppl 2):S7-11. [PMID: 1468055]

77. O'Sullivan SB, Schmitz TJ, editors. Physical rehabilitation: assessment and treatment. 5th ed. Philadelphia (PA): F. A. Davis; 2006.

78. Tuohimaa P. Vestibular disturbances after acute mild head injury. Acta Otolaryngol Suppl. 1978;359:3-67. [PMID: 310630]

79. De Kruijk JR, Leffers P, Menheere PP, Meerhoff S, Rutten J, Twijnstra A. Prediction of post-traumatic complaints after mild traumatic brain injury: Early symptoms and biochemical markers. J Neurol Neurosurg Psychiatry. 2002; 73(6):727-32. [PMID: 12438478]

DOI:10.1136/jnnp.73.6.727

80. Binder LM. A review of mild head trauma. Part II: Clinical implications. J Clin Exp Neuropsychol. 1997;19(3): 432-57. [PMID: 9268817] DOI:10.1080/01688639708403871

81. Ingebrigtsen T, Waterloo K, Marup-Jensen S, Attner E, Romner B. Quantification of post-concussion symptoms 3 months after minor head injury in 100 consecutive patients. J Neurol. 1998;245(9):609-12. [PMID: 9758300] DOI:10.1007/s004150050254

82. Van der Naalt J. Prediction of outcome in mild to moderate head injury: A review. J Clin Exp Neuropsychol. 2001; 23(6):837-51. [PMID: 11910548] DOI:10.1076/jcen.23.6.837.1018

83. Bryant R, Harvey AG. Postconcussive symptoms and posttraumatic stress disorder after mild traumatic brain injury. J Nerv Ment Dis. 1999;187(5):302-5. [PMID: 10348085] DOI:10.1097/00005053-199905000-00006

84. Jacobson RR. The post-concussional syndrome: Physiogenesis, psychogenesis and malingering. An integrative model. J Psychosom Res. 1995;39(6):675-93.

[PMID: 8568727] DOI:10.1016/0022-3999(95)00006-5

85. Chamelian L, Feinstein A. Outcome after mild to moderate traumatic brain injury: The role of dizziness. Arch Phys Med Rehabil. 2004;85(10):1662-66. [PMID: 15468028] DOI:10.1016/j.apmr.2004.02.012

86. Gannon RP, Willson GN, Roberts ME, Pearse HJ. Auditory and vestibular damage in head injuries at work. Arch Otolaryngol. 1978;104(7):404-8. [PMID: 666649]

87. Gurr B, Moffat N. Psychological consequences of vertigo and the effectiveness of vestibular rehabilitation for brain 
injury patients. Brain Inj. 2001;15(5):387-400.

[PMID: 11350653]

DOI:10.1080/02699050010005904

88. Keyser-Marcus LA, Bricout JC, Wehman P, Campbell LR, Cifu DX, Englander J, High W, Zafonte RD. Acute predictors of return to employment after traumatic brain injury: A longitudinal follow-up. Arch Phys Med Rehabil. 2002;83(5):635-41. [PMID: 11994802]

DOI:10.1053/apmr.2002.31605

89. Haaland KY, Temkin N, Randahl G, Dikmen S. Recovery of simple motor skills after head injury. J Clin Exp Neuropsychol. 1994;16(3):448-56. [PMID: 7929712]

DOI:10.1080/01688639408402655

90. Chaplin D, Deitz J, Jaffe KM. Motor performance in children after traumatic brain injury. Arch Phys Med Rehabil. 1993;74(2):161-64. [PMID: 8431100]

91. Kuhtz-Buschbeck JP, Hoppe B, Gölge M, Dreesmann M, Damm-Stünitz U, Ritz A. Sensorimotor recovery in children after traumatic brain injury: Analyses of gait, gross motor, and fine motor skills. Dev Med Child Neurol. 2003;45(12):821-28. [PMID: 14667074]

DOI: 10.1017/S001216220300152X

92. Gray C, Cantagallo A, Della Sala S, Basaglia N. Bradykinesia and bradyphrenia revisited: Patterns of subclinical deficit in motor speed and cognitive functioning in headinjured patients with good recovery. Brain Inj. 1998;12(5): 429-41. [PMID: 9591145] DOI: $10.1080 / 026990598122548$

93. Incoccia C, Formisano R., Muscato P, Reali G, Zoccolotti P. Reaction and movement times in individuals with chronic traumatic brain injury with good motor recovery. Cortex. 2004;40(1):111-15. [PMID: 15070006] DOI:10.1016/S0010-9452(08)70924-9

94. Di Russo F, Incoccia C, Formisano R, Sabatini U, Zoccolotti P. Abnormal motor preparation in severe traumatic brain injury with good recovery. J Neurotrauma. 2005; 22(2):297-312. [PMID: 15716635]

DOI:10.1089/neu.2005.22.297

95. Millis SR, Rosenthal M, Novack TA, Sherer M, Nick TG, Kreutzer JS, High WM Jr, Ricker JH. Long-term neuropsychological outcome after traumatic brain injury. J Head Trauma Rehabil. 2001;16(4):343-55. [PMID: 11461657] DOI:10.1097/00001199-200108000-00005

96. Asikainen I, Nybo T, Muller K, Sarna S, Kaste M. Speed performance and long-term functional and vocational outcome in a group of young patients with moderate or severe traumatic brain injury. Eur J Neurol. 1999;6(2): 179-85. [PMID: 10053230]

DOI:10.1111/j.1468-1331.1999.tb00011.x

97. Clifton GL, Kreutzer JS, Choi SC, Devany CW, Eisenberg HM, Foulkes MA, Jane JA, Marmarou A, Marshall LF. Relationship between Glasgow Outcome Scale and neuro- psychological measures after brain injury. Neurosurgery. 1993;33(1):34-39. [PMID: 8355845]

DOI:10.1097/00006123-199307000-00005

98. Marshall S, Teasell R, Bayona N, Lippert C, Chundamala J, Villamere J, Mackie D, Cullen N, Bayley M. Motor impairment rehabilitation post acquired brain injury. Brain Inj. 2007;21(2):133-60. [PMID: 17364529] DOI:10.1080/02699050701201383

99. Kapoor N, Ciuffreda KJ. Vision disturbances following traumatic brain injury. Curr Treat Options Neurol. 2002; 4(4):271-80. [PMID: 12036500] DOI:10.1007/s11940-002-0027-z

100. Kapoor N, Ciuffreda K, Han Y. Oculomotor rehabilitation in acquired brain injury: A case series. Arch Phys Med Rehabil. 2004;85(10):1667-78. [PMID: 15468029] DOI:10.1016/j.apmr.2003.12.044

101. Kasten E, Sabel BA. Visual field enlargement after computer training in brain-damaged patients with homonymous deficits: An open pilot trial. Restor Neurol Neurosci. 1995; 8(3):113-27.

102. Goldenberg G, Müllbacher W, Nowak A. Imagery without perception-A case study of anosognosia for cortical blindness. Neuropsychologia. 1995;33(11):1373-82. [PMID: 8584175] DOI:10.1016/0028-3932(95)00070-J

103. Ball K, Owsley C. The useful field of view test: A new technique for evaluating age-related declines in visual function. J Am Optom Assoc. 1992;64(1):71-79. [PMID: 8454831]

104. Ikeda M, Takeuchi T. Influence of foveal load on the functional visual field. Percept Psychophys. 1975;18(4):255-60.

105. Owsley C, Ball K, Keeton DM. Relationship between visual sensitivity and target localization in older adults. Vision Res. 1995;35(4):579-87. [PMID: 7900297] DOI:10.1016/0042-6989(94)00166-J

106. Fisk GD, Novack T, Mennemeier M, Roenker D. Useful field of view after traumatic brain injury. J Head Trauma Rehabil. 2002;17(1):16-25. [PMID: 11860326] DOI:10.1097/00001199-200202000-00004

107. Fisk GD, Owsley C, Mennemeier M. Vision, attention, and self-reported driving behaviors in community-dwelling stroke survivors. Arch Phys Med Rehabil. 2002;83(4): 469-77. [PMID: 11932847]

DOI:10.1053/apmr.2002.31179

108. Ylvisaker M, Jacobs HE, Feeney T. Positive supports for people who experience behavioral and cognitive disability after brain injury: A review. J Head Traum Rehabil. 2003; 18(1):7-32. [PMID: 12802235] DOI:10.1097/00001199-200301000-00005

109. Pössl J, Jürgensmeyer S, Karlbauer F, Wenz C, Goldenberg G. Stability of employment after brain injury: A 7-year follow-up study. Brain Inj. 2001:15(1):15-27. 
[PMID: 11201311]

DOI:10.1080/02699050150209093

110. Kleppel JB, Lincoln AE, Winston FK. Assessing headinjury survivors of motor vehicle crashes at discharge from trauma care. Am J Phys Med Rehabil. 2002;81(2): 114-22. [PMID: 11807348] DOI:10.1097/00002060-200202000-00007

111. Lahz S, Bryant RA. Incidence of chronic pain following traumatic brain injury. Arch Phys Med Rehabil. 1996; 77(9):889-91. [PMID: 8822679]

DOI:10.1016/S0003-9993(96)90275-0

112. Jacobson L, Mariano AJ. General considerations of chronic pain. In: Loeser JD, Bonica JJ, editors. Bonica's management of pain. Philadelphia (PA): Lippincott Williams \& Wilkins; 2001. p. 241-54.

113. Walker WC. Pain pathoetiology after TBI: Neural and nonneural mechanisms. J Head Trauma Rehabil. 2004; 19(1):72-81. [PMID: 14732832]

DOI:10.1097/00001199-200401000-00007

114. Bazarian JJ, Wong T, Harris M, Leahey N, Mookerjee S, Dombovy M. Epidemiology and predictors of postconcussive syndrome after minor head injury in an emergency population. Brain Inj. 1999;13(3):173-89.

[PMID: 10081599]

DOI:10.1080/026990599121692

115. Headache Classification Committee of the International Headache Society. Classification and diagnostic criteria for headache disorders, cranial neuralgias and facial pain. Cephalgia. 1988;8(Suppl 7):1-96. [PMID: 3048700]

116. Uomoto JM, Esselman PC. Traumatic brain injury and chronic pain: Differential types and rates by head injury severity. Arch Phys Med Rehabil. 1993;74(1):61-64. [PMID: 8420522]

117. Couch JR, Bearss C. Chronic daily headache in the posttrauma syndrome: Relation to extent of head injury. Headache. 2001;41(6):559-64. [PMID: 11437891]

DOI:10.1046/j.1526-4610.2001.041006559.x

118. Yamaguchi M. Incidence of headache and severity of head injury. Headache. 1992;32(9):427-31. [PMID: 1446984] DOI:10.1111/j.1526-4610.1992.hed3209427.x

119. De Benedittis G, De Santis A. Chronic post-traumatic headache: Clinical, psychopathological features and outcome determinants. J Neurosurg Sci. 1983;27(3):177-86. [PMID: 6663350]

120. Walker WC, Seel RT, Curtiss G, Warden DL. Headache after moderate and severe traumatic brain injury: A longitudinal analysis. Arch Phys Med Rehabil. 2005;86(9): 1793-1800. [PMID: 16181945] DOI:10.1016/j.apmr.2004.12.042

121. Packard RC, Ham LP. Posttraumatic headache: Determining chronicity. Headache. 1993;33(3):133-34.
[PMID: 8486509]

DOI:10.1111/j.1526-4610.1993.hed3303133.x

122. Baandrup L, Jensen R. Chronic post-traumatic headache-A clinical analysis in relation to the International Headache Classification 2nd Edition. Cephalalgia. 2005; 25(2):132-38. [PMID: 15658950]

DOI:10.1111/j.1468-2982.2004.00818.x

Erratum in: Cephalalgia. 2005;25(3):240.

123. Lew HL, Lin PH, Fuh JL, Wang SJ, Clark DJ, Walker WC. Characteristics and treatment of headache after traumatic brain injury: A focused review. Am J Phys Med Rehabil. 2006;85(7):619-27. [PMID: 16788394] DOI:10.1097/01.phm.0000223235.09931.c0

124. Rasmussen BK, Jensen R, Schroll M, Olesen J. Epidemiology of headache in a general population-A prevalence study. J Clin Epidemiol. 1991;44(11):1147-57.

[PMID: 1941010]

DOI:10.1016/0895-4356(91)90147-2

125. Ouellet MC, Beaulieu-Bonneau S, Morin CM. Insomnia in patients with traumatic brain injury: Frequency, characteristics, and risk factors. J Head Trauma Rehabil. 2006; 21(3):199-212. [PMID: 16717498] DOI:10.1097/00001199-200605000-00001

126. American Psychiatric Association. Diagnostic and statistical manual of mental disorders: DSM-IV-TR. 4th ed. Washington (DC): American Psychiatric Association; 1994.

127. American Sleep Disorders Association. The international classification of sleep disorders, revised: Diagnostic and coding manual. Rochester (MN): American Sleep Disorders Association; 1997.

128. Flanagan SR, Greenwald D, Wieber S. Pharmacological treatment of insomnia for individuals with brain injury. J Head Trauma Rehabil. 2007;22(1):67-70.

[PMID: 17235234]

DOI:10.1097/00001199-200701000-00009

129. Clinchot DM, Bogner J, Mysiw WJ, Fugate L, Corrigan J. Defining sleep disturbance after brain injury. Am J Phys Med Rehabil. 1998;77(4):291-95. [PMID: 9715917] DOI:10.1097/00002060-199807000-00006

130. Cohen M, Oksenberg A, Snir D, Stern MJ, Groswasser Z. Temporally related changes of sleep complaints in traumatic brain injured patients. J Neurol Neurosurg Psychiatry. 1992; 55(4):313-15. [PMID: 1583518]

DOI:10.1136/jnnp.55.4.313

131. Dikmen S, McLean A, Temkin N. Neuropsychological and psychosocial consequences of minor head injury. J Neurol Neurosurg Psychiatry. 1986;49(11):1227-32. [PMID: 3794728$]$ DOI:10.1136/jnnp.49.11.1227

132. Fichtenberg NL, Zafonte RD, Putnam S, Mann NR, Millard AE. Insomnia in a post-acute brain injury sample. 
Brain Inj. 2002;16(3):197-206. [PMID: 11874613]

DOI:10.1080/02699050110103940

133. Hibbard MR, Uysal S, Sliwinski M, Gordon WA. Undiagnosed health issues in individuals with traumatic brain injury living in the community. J Head Trauma Rehabil. 1998;13(4):47-57. [PMID: 9651239] DOI:10.1097/00001199-199808000-00005

134. Keshavan MS, Channabasavanna SM, Reddy GN. Posttraumatic psychiatric disturbances: Patterns and predictors of outcome. Br J Psychiatry. 1981;138:157-60. [PMID: 7260498] DOI:10.1192/bjp.138.2.157

135. Perlis ML, Artiola L, Giles DE. Sleep complaints in chronic postconcussion syndrome. Percept Mot Skills. 1997;84(2):595-99. [PMID: 9106853]

136. Segalowitz SJ, Lawson S. Subtle symptoms associated with self-reported mild head injury. J Learn Disabil. 1995; 28(5):309-19. [PMID: 7775851] DOI:10.1177/002221949502800507

137. Ford DE, Kamerow DB. Epidemiologic study of sleep disturbances and psychiatric disorders. An opportunity for prevention? JAMA. 1989;262(11):1479-84. [PMID: 2769898] DOI:10.1001/jama.262.11.1479

138. Ohayon MM, Caulet M, Priest RG, Guilleminault C. DSM-IV and ICSD-90 insomnia symptoms and sleep dissatisfaction. Br J Psychiatry. 1997;171:382-88.

[PMID: 9373431]

DOI:10.1192/bjp.171.4.382

139. Parsons LC, Ver Beek D. Sleep-awake patterns following cerebral concussion. Nurs Res. 1982;31(5):260-64.

[PMID: 6922465] DOI:10.1097/00006199-198231050-00002

140. Kaufman Y, Tzischinsky O, Epstein R, Etzioni A, Lavie P, Pillar G. Long-term sleep disturbances in adolescents after minor head injury. Pediatr Neurol. 2001;24(2):129-34. [PMID: 11275462] DOI:10.1016/S0887-8994(00)00254-X

141. Guilleminault C, Yuen KM, Gulevich MG, Karadeniz D, Leger D, Philip P. Hypersomnia after head-neck trauma: A medicolegal dilemma. Neurology. 2000;54(3):653-59. [PMID: 10680799]

142. Wu R, Bao J, Zhang C, Deng J, Long C. Comparison of sleep condition and sleep-related psychological activity after cognitive-behavior and pharmacological therapy for chronic insomnia. Psychother Psychosom. 2006;75(4): 220-28. [PMID: 16785771]

DOI:10.1159/000092892

143. Grunstein R. Insomnia. Diagnosis and management. Aust Fam Physician. 2002;31(11):995-1000. [PMID: 12471955]

144. Terzano MG, Rossi M, Palomba V, Smerieri A, Parrino L. New drugs for insomnia: Comparative tolerability of zopiclone, zolpidem and zaleplon. Drug Saf. 2003;26(4):261-82.
[PMID: 12608888]

DOI:10.2165/00002018-200326040-00004

145. Holbrook AM, Crowther R, Lotter A, Cheng C, King D. Meta-analysis of benzodiazepine use in the treatment of insomnia. CMAJ. 2000;162(2):225-33. [PMID: 10674059]

146. Obermeyer WH, Benca RM. Effects of drugs on sleep. Neurol Clin. 1996;14(4):827-40. [PMID: 8923497] DOI:10.1016/S0733-8619(05)70287-5

147. Rosenberg RP. Sleep maintenance insomnia: Strengths and weaknesses of current pharmacological therapies. Ann Clin Psychiatry. 2006;18(1):49-56. [PMID: 16517453] DOI:10.1080/10401230500464711

148. Mendelson WB. A review of the evidence for the efficacy and safety of trazodone in insomnia. J Clin Psychiatry. 2004;66(4):469-76. [PMID: 15816789]

149. Levenson JL. Prolonged QT interval after trazodone overdose. Am J Psychiatry. 1999;156(6):969-70. [PMID: 10360146]

150. Winokur A, Sateia MJ, Hayes JB, Bayles-Dazet W, MacDonald MM, Gary KA. Acute effects of mirtazapine on sleep continuity and sleep architecture in depressed patients: A pilot study. Biol Psychiatry. 2000;48(1):75-78.

[PMID: 10913511]

DOI:10.1016/S0006-3223(00)00882-9

151. Wingen M, Bothmer J, Langer S, Ramaekers JG. Actual driving performance and psychomotor function in healthy subjects after acute and subchronic treatment with escitalopram, mirtazapine, and placebo: A crossover trial. J Clin Psychiatry. 2005;66(4):436-43. [PMID: 15816785]

152. Wagner J, Wagner ML. Non-benzodiazepines for the treatment of insomnia. Sleep Med Rev. 2000;4(6):551-81. [PMID: 12531036]

DOI:10.1053/smrv.2000.0126

153. Scharf MD, Roth T, Vogel GW, Walsh JK. A multicenter, placebo-controlled study evaluating zolpidem in the treatment of chronic insomnia. J Clin Psychiatry. 1994; 55(5):192-99. [PMID: 8071269]

154. Moen MD, Plosker GL. Zolpidem extended-release. CNS Drugs. 2006;20(5):419-26. [PMID: 16696581] DOI:10.2165/00023210-200620050-00006

155. Yang W, Dollear M, Muthukrishnan SR. One rare side effect of zolpidem-Sleepwalking: A case report. Arch Phys Med Rehabil. 2005;86(6):1265-66. [PMID: 15954071] DOI:10.1016/j.apmr.2004.11.022

156. Allen D, Curran HV, Lader M. The effects of single doses of CL284,846, lorazepam, and placebo on psychomotor and memory function in normal male volunteers. Eur J Clin Pharmacol. 1993;45(4):313-20. [PMID: 8299662] DOI:10.1007/BF00265947

157. Walsh JK, Fry J, Erwin CW, Scharf M, Roth T, Vogel GW. Efficacy and tolerability of 14-day administration of zaleplon 
$5 \mathrm{mg}$ and $10 \mathrm{mg}$ for the treatment of primary insomnia. Clin Drug Invest. 1998;16:347-54.

158. Bocca ML, Le Doze F, Etard O, Pottier M, L'Hoste J, Denise P. Residual effect of zolpidem $10 \mathrm{mg}$ and zopiclone $7.5 \mathrm{mg}$ versus flunitrazepam $1 \mathrm{mg}$ and placebo on driving performance and ocular saccades. Psychopharmacology (Berl). 1999;143(4):373-79. [PMID: 10367554] DOI:10.1007/s002130050961

159. Najib J. Eszopiclone, a nonbenzodiazepine sedative-hypnotic agent for the treatment of transient and chronic insomnia. Clin Ther. 2006;28(4):491-516. [PMID: 16750462] DOI:10.1016/j.clinthera.2006.04.014

160. Roth T, Walsh JK, Krystal A, Wessel T, Roehrs TA. An evaluation of the efficacy and safety of eszopiclone over 12 months in patients with chronic primary insomnia. Sleep Med. 2005;6(6):487-95. [PMID: 16230048] DOI:10.1016/j.sleep.2005.06.004

161. Azouvi A, Couillet J, Leclercq M, Martin Y, Asloun S, Rousseaux M. Divided attention and mental effort after severe traumatic brain injury. Neuropsychologia. 2004; 42(9):1260-68. [PMID: 15178177] DOI:10.1016/j.neuropsychologia.2004.01.001

162. Fisk JD, Ritvo PG, Ross L, Haase DA, Marrie TJ, Schlech WF. Measuring the functional impact of fatigue: Initial validation of the fatigue impact scale. Clin Infect Dis. 1994;18(Suppl 1):S79-83. [PMID: 8148458]

163. Smets EM, Garssen B, Bonke B, De Haes JC. The Multidimensional Fatigue Inventory (MFI) psychometric qualities of an instrument to assess fatigue. J Psychosom Res. 1995;39(3):315-25. [PMID: 7636775] DOI:10.1016/0022-3999(94)00125-O

164. Fisk JD, Pontefract A, Ritvo PG, Archibald CJ, Murray TJ. The impact of fatigue on patients with multiple sclerosis. Can J Neurol Sci. 1994;21(1):9-14. [PMID: 8180914]

165. Middleboe T, Anderson HS, Birket-Smith M, Friis ML. Minor head injury: Impact on general health after 1 year.
A prospective follow-up study. Acta Neurol Scand. 1992; 85(1):5-9. [PMID: 1546534]

166. Krupp LB, LaRocca NG, Muir-Nash J, Steinberg AD. The fatigue severity scale. Application to patients with multiple sclerosis and systemic lupus erythematosus. Arch Neurol. 1989;46(10):1121-23. [PMID: 2803071]

167. Borgaro SR, Gierok S, Caples H, Kwasnica C. Fatigue after brain injury: Initial reliability study of the BNI Fatigue Scale. Brain Inj. 2004;18(7):685-90. [PMID: 15204329] DOI:10.1080/02699050310001646080

168. Koskinen S. Quality of life 10 years after a very severe traumatic brain injury (TBI): The perspective of the injured and the closest relative. Brain Inj. 1998;12(8): 631-48. [PMID: 9724835] DOI:10.1080/026990598122205

169. Olver JH, Ponsford JL, Curran CA. Outcome following traumatic brain injury: A comparison between 2 and 5 years after injury. Brain Inj. 1996;10(11):841-48.

DOI:10.1080/026990596123945

170. Massagli TL, Michaud LJ, Rivara FP. Association between injury indices and outcome after severe traumatic brain injury in children. Arch Phys Med Rehabil. 1996; 77(2):125-32. [PMID: 8607735] DOI:10.1016/S0003-9993(96)90156-2

171. Stuss DT, Stethem LL, Hugenholtz H, Picton T, Pivik J, Richard MT. Reaction time after head injury: Fatigue, divided and focused attention, and consistency of performance. J Neurol Neurosurg Psychiatry. 1989;52(6):742-48. [PMID: 2746267]

DOI:10.1136/jnnp.52.6.742

172. Crépeau F, Scherzer P. Predictors and indicators of work status after traumatic brain injury: A meta-analysis. Neuropsychol Rehabil. 1993;3(1):5-35. DOI:10.1080/09602019308401421

Submitted for publication August 20, 2008. Accepted in revised form December 11, 2008. 